\title{
Breast Cancer Metastasis to the Cerebellum: A Rare Event in Our Setting, the Adverse Impact of Late Presentation-Case Report
}

\author{
Odebode Timothy Olugbenga ${ }^{1^{*}}$, Olatoke Samuel Adegboyega ${ }^{2}$, Rahman Ganiyu Adebisi ${ }^{2}$, \\ Afolayan Enoch Abiodun Olakojo ${ }^{2}$, Oyinloye Olalekan Ibukun ${ }^{2}$, Agboola John Owoade ${ }^{2}$ \\ ${ }^{I}$ Division of Neurosurgery, Department of Surgery, University of Ilorin Teaching Hospital, Kwara state, Nigeria \\ ${ }^{2}$ Department of Surgery, University of Ilorin \& University of Ilorin Teaching Hospital, Kwara State, Nigeria \\ *Corresponding Author: T.O. Odebode, Division of Neurosurgery, Department of Surgery, University of \\ Ilorin Teaching Hospital, Kwara state, Nigeria, Email: odebodetodr@yahoo.com
}

\begin{abstract}
Although breast cancer is the commonest cancer in Nigerian women (just as it is worldwide), metastasis to the cerebral parenchyma is very rare and spread to the cerebellum has not been reported. Of more than 37 childhood and adult cerebellar cancers managed in this center (which serves six adjoining states in Nigeria) over 17 years, this case constitutes the first to have arisen from a breast cancer. The 33year-old woman developed a breast lump for which she did not consult a physician for 2 years. Following a simple mastectomy, she had a six-month course of Adriamycin based adjuvant chemotherapy. The histology was an invasive ductal carcinoma. Eight months after surgery, she noted a gait ataxia but could not consult her physician for review and investigation till another six months because of financial constraint. A delayed cranial CT revealed a solitary cerebellar tumour with obstructive hydrocephalus for which surgery was counselled. Again, she declined a sub-occipital craniectomy opting for an alternative spiritual healing for another six months during which she became blind, deaf, and moribund with a Karnofsky Performance Score of 40. At this point she submitted to the option of CSF diversion followed by tumour excision but died 40 days after -definitive surgery. Histology confirmed features of invasive ductal carcinoma. This report illustrates the rarity of cerebellar metastasis from breast cancer in our environment and the adverse impact on outcome of late presentation, finance and faulty religious belief.
\end{abstract}

Keywords: Breast cancer, Metastasis, Cerebellum, Late presentation, Finance, Religion

\section{INTRODUCTION}

Cerebellar metastases are considered a negative prognostic factor in patients with systemic cancers [1]. Although breast cancer is the most common cancer and the second principal cause of cancer deaths in women worldwide [2], metastasis to the brain in Nigerian women is rare. Brain metastases most commonly involve the cerebral parenchyma [3] and very rarely the cerebellum. Of cases of breast cancer in Nigerians, $50 \%$ will develop metastasis in bones (34\%), soft tissue (18\%), pleura (13\%), lung (12\%), liver (9\%), and brain (3\%) [3]. Amongst 225 consecutive cases of breast cancer treated at a University Teaching Hospital in Northern Nigeria, metastases occurred in the lung $(6.2 \%)$, liver $(3.6 \%)$, bone $(2.2 \%)$ and spinal cord $(0.9 \%)$ but none in the brain. [4].

Furthermore, $64 \%$ of Nigerian patients with breast cancer present late after six months of onset of symptoms [5] usually due to financial constraint which delays conduct of appropriate investigations and surgical treatment especially in a "pay as you eat" health care system which is devoid of a widely-implemented health insurance policy. We report this first case of cerebellar metastasis from primary breast carcinoma among Nigerian women presenting in our setting to illustrate its rarity and the impact on outcome of late presentation, financial constraint engendering delayed investigation and treatment, and faulty religious belief.

\section{CASE RePort}

A referred 33-year-old female Nigerian presented late to our facility 2 years after developing a left breast lump. Examination was positive for an ulcerated fungating left breast mass with ipsilateral axillary discreet lymph nodes consistent with Manchester Stage 3. There was no clinical or radiological evidence 
of systemic metastasis. Tru-cut needle biopsy and histology revealed an invasive ductal cell carcinoma (IDCC). After simple mastectomy and level-II axillary dissection, H\&E staining demonstrated the "comedo" pattern of an IDCC and she was commenced on oral tamoxifen and a six-month course of intravenous Adriamycin, cyclophosphamide, methotrexate, and 5florouracil. Two months following completion of chemotherapy, she developed headache, vomiting, gait ataxia, and dysdiadochokinesia suggestive of a cerebellar lesion. A cranial CT was not done immediately due to financial constraint. Six months later the CT revealed a solitary hypodense left cerebellar lesion with peripheral contrast enhancement, perilesional oedema and obstructive hydrocephalus (Fig. 1).

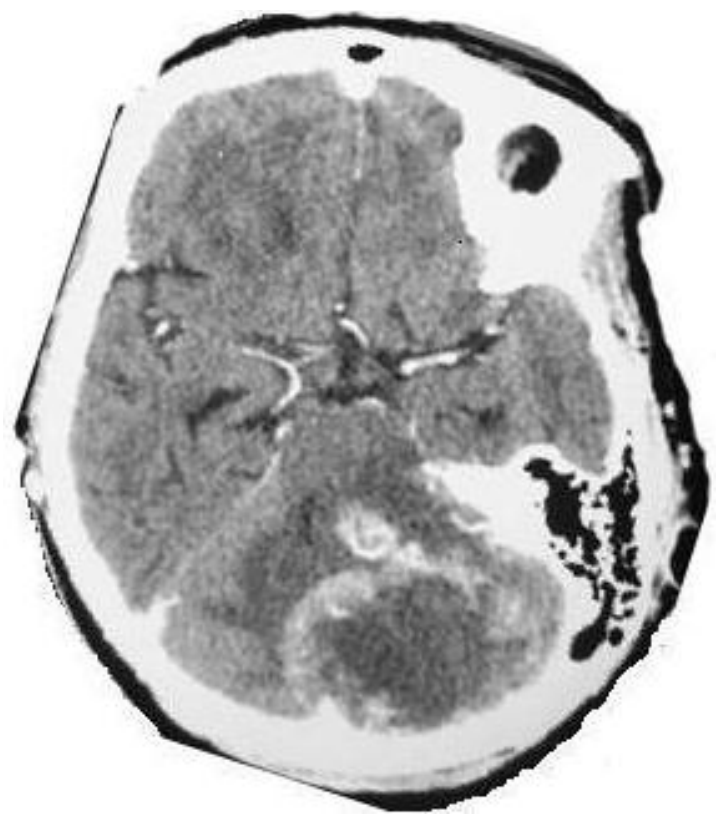

Figure1Preoperative contrast enhanced cranial computed tomography in a Nigerian patient with cerebellar metastasis from breast carcinoma showing a solitary left cerebellar hypodense mass with peripheral ring enhancement, perilesional oedema and complicating obstructive hydrocephalus.

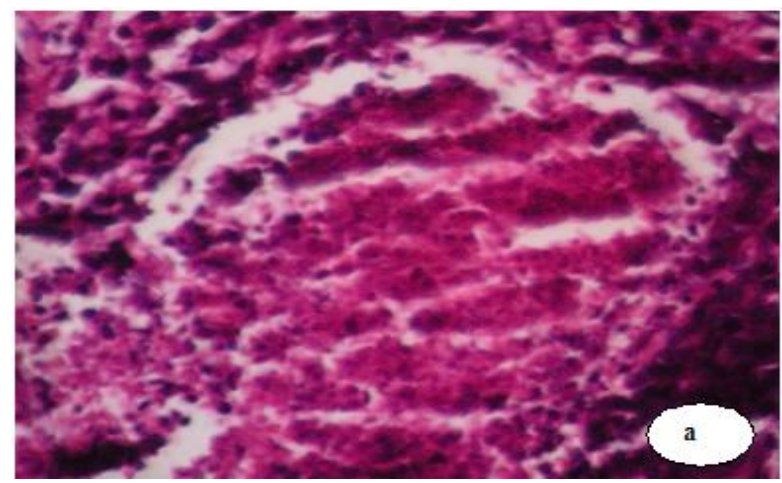

Figure2. (a) Photomicrograph showing features of metastatic invasive ductal cell carcinoma: "comedo pattern" (H\&Ex400) in the cerebellum. (b) demonstrates vascular emboli in the cerebellar tumour (H\&Ex400).

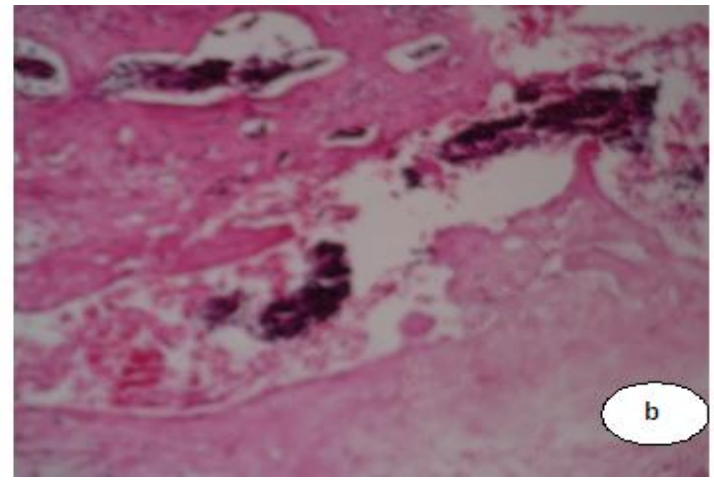

She declined surgical intervention in favour of alternative faith healing claiming that her condition was satanic in origin and would not benefit from orthodox medical or surgical therapies. She discharged herself against medical advice only to re-present 6 months later with total blindness, deafness, worse cerebellar signs and a Karnofsky Performance Score (KPS) of 40. A repeat cranial CT was not done because of economic constraint. Her progressive neurologic deterioration informed an emergency cerebrospinal fluid (CSF) diversion which was followed by a sub-occipital craniectomy and tumour excision 2 weeks later. Cerebrospinal fluid diversion is a procedure that is used to drain fluid from the brain and spinal cord in which a shunt is placed in a ventricle of the brain; and threaded under the skin to another part of the body, usually the abdomen. In this case a Chhabra 'SLIT N SPRING' hydrocephalus shunt system (G. Surgiwear Ltd, India) was employed to drain CSF from the right lateral ventricle into the abdomen. CSF cytology was negative for malignant cells and culture-negative. Histological verification of excised tumour showed large metastatic malignant epithelial cells of invasive ductal carcinoma-comedo growth pattern (Fig. 2a) with areas of vascular and lymphatic tumour permeation and mononuclear cell infiltration and haemorrhage [Fig. 2b]. She died from a cardio-respiratory arrest at 40 days after surgery and besides the parents declined consent for post-mortem examination. This report illustrates the rarity of cerebellar metastasis from breast cancer in our environment and the adverse impact on outcome of late presentation, finance and faulty religious belief. 


\section{DISCUSSION}

The hallmarks of breast cancer in Nigerian women and in other resource limited African societies are late presentation in advanced stages [6], lack of adequate mammography screening programmes, preponderance of pre-menopausal patients, and a high morbidity and mortality as partly exemplified by the current patient. For women with symptomatic breast cancer, prolonged delay, defined arbitrarily as an interval greater than 3 months from first detection to time of diagnosis and treatment has been shown to be associated with increased tumor size, more advanced stage of disease and poor long term survival [7]. The target patient presenting at 2 years after symptom onset with the vicious cycle of financial constraint, delayed investigations and delayed surgical treatment typifies the typical findings in Nigerian women. Many authors have attributed late presentation prevalent among Nigerian women with breast cancer to lack of cancer awareness, religious beliefs, attitudes, and poor knowledge about cancer [3-5]. Compared with other nationals, an estimated 20-30\% of Caucasian women wait for at least 3 months before seeking help for breast cancer symptoms [8] while over $70 \%$ of Nigerian women present in advanced stages [35].

The relative rarity of cerebellar metastasis in Nigerians is probably due to the fact that many patients do not survive long enough to develop brain metastases, or due to shortage of funds, manpower and radio-diagnostic facilities for its detection. The patient's claim that her condition was satanic in origin and that she would not benefit from orthodox medical treatment basically embodies a faulty religious belief with poverty and ignorance. This scenery of believing in alternative medicine or spiritual healing is commonly encountered among Nigerians. It often engenders a delay in instituting appropriate medical and especially surgical treatment and finally a higher morbidity and mortality rates as exemplified by this patient.

Because cerebellar metastases may cause obstructive hydrocephalus and brain stem compression, survival of patients with cerebellar metastases has been reported as more disappointing than that reported for cerebral hemispheric metastases [1]. A study of 109 patients with cerebellar metastases [1] revealed longer mean survival time in patients with single metastasis (vs multiple), pre-treatment KPS $\geq 70$ and those who had surgical resection plus whole brain radiation (WBRT) compared with those who had WBRT alone [1]. Surgical resection of brain metastases is particularly indicated in patients with good prognostic factors including supra-tentorial location of metastases, good KPS, single metastatic lesion, young age, minimal extra-cranial disease, and supratentorial location of metastases [1]. The latter three factors should have enhanced the patient's survival following tumour resection and CSF diversion but the low performance (KPS) score and the tumour's infra-tentorial location most likely constituted significant morbidity and mortality risks.

\section{CONClusion}

To the best of our knowledge, we report the first case of cerebellar metastasis from breast cancer among Nigerian women while illustrating the adverse impact of late presentation, faulty religious belief and financial constraint on outcome.

\section{DEClARATION OF CONFLICT OF INTEREST}

The authors declare that there is no conflict of interest regarding the publication of this paper.

\section{REFERENCES}

[1] Yoshida S, Takahashi H: Cerebellar metastases in patients with cancer. Surg. Neurol.2009; 71(2):184-187.

[2] Adebamowo CA, Ajayi OO: Breast cancer in Nigeria. W. Afr J Med 2000; 19:179-191.

[3] Uche EEO: Cancer awareness among a Nigerian population. Trop Doct 1999; 29:3940.

[4] Odigie VI, Yusufu LMD, Rafindadi A, da Rocha-Afodu JT: Breast Carcinoma in Zaria (North Western Nigeria) 1989-2002. Some clinicopathological observations. Nig. J. Surg. 2003; 9(2):46-50.

[5] Odusanya OO, Tayo OO: Breast cancer knowledge, attitudes and practice among nurses in Lagos, Nigeria. ActaOncologica 2001; 40(7), 844-848.

[6] Okobia MN, Bunker CH, Okonofua FE, Osime U: Knowledge, attitude and practice of Nigerian women towards breast cancer: A cross-sectional study. World Journal of surgical oncology 2006; 4:11 doi:10.1186/1477-7819-4-11.

[7] Neave LM, Mason BH, Kay RG: Does delay in diagnosis of breast cancer affect survival? Breast Cancer Res Treat 1990; 15(2):103-108. 
Breast Cancer Metastasis to the Cerebellum: A Rare Event in Our Setting, the Adverse Impact of Late Presentation- Case Report

[8] Richards MA, Westcombe AM, Love SB, Littlejohns P, Ramirez AJ: Influence of delay on survival in patients with breast cancer: a systematic review. Lancet 1999; 353(9159):1119-1126.
[9] Eichler AF, Kuter I, Ryan P, Schapira L, Younger J, Henson JW: Survival in patients with brain metastases from breast cancer; the importance of HER-2 status. Cancer 2008; 1; 112(11) 2359-2367.

Citation: Odebode Timothy Olugbenga, Olatoke Samuel Adegboyega, Rahman Ganiyu Adebisi, Afolayan Enoch Abiodun Olakojo, Oyinloye Olalekan Ibukun, Agboola John Owoade. Breast Cancer Metastasis to the Cerebellum: A Rare Event in Our Setting, the Adverse Impact of Late Presentation-Case Report. ARC Journal of Clinical Case Reports.2017; 3(3):5-8. doi:dx.doi.org/10.20431/2455-9806.0303002.

Copyright: (c) 2017 Authors. This is an open-access article distributed under the terms of the Creative Commons Attribution License, which permits unrestricted use, distribution, and reproduction in any medium, provided the original author and source are credited. 